\title{
Signs of Art
}

\section{- BERND KLEIMANN}

The question I would like to discuss in this essay is one of the most prominent problems in the area of philosophical aesthetics. Although it sounds simple, it requires a thorough investigation. The question is: "What is art?" The answer I would like to propose is very simple at first sight and runs like this: works of art constitute a particular class of signs that can and should be analyzed with regard to their particular semantic, syntactic and pragmatic properties. In the following passages I will try to explain the reasons for this approach focussing on art as a class of signs. In order to do so, I shall make two steps: first I will discuss the thesis that works of art are artifacts, and then I will turn to the particular properties of artistic signs.

At the very beginning it seems reasonable to me to transform the question concerning the nature of art into a question about the nature of works of art. The reason for this is the well-known ambiguity of the word "art". Firstly it refers to skills or faculties, secondly it refers to objects that are exposed, praised, criticized, and sold as entities of a special kind - namely: as works of art. In my paper I will only consider the latter meaning of the word "art". But what is a work of art? What is it that paintings, operas, novels, poems, video installations, happenings, architectural masterpieces or sculptures have in common?

The first property considered by many theories of art is expressed in the conviction that works of art must be things. If we suppose that things are physical objects that can be located in time and space, then it seems to follow that works of art - like books, paintings or sculptures - are material things. Additionally, works of art must be regarded as a certain sort of things, since they are produced by man - in contrast to boulders, waterfalls or may-bugs. Only artifacts are entitled to claim the status of a work of art. So the gulf stream, the Mount Everest, a panda bear or a redwood tree are no works of art. But while we can admit this, another question arises: What are the characteristics of works of art as artifacts? 
A first explanation is offered by George Dickie: "Typically an artifact is produced by altering some preexisting material: by joining two pieces of material, by cutting some material, by sharpening some material, and so on. This is usually done so that the altered material can be used to do something." According to this opinion artifacts are material objects that are shaped by man and serve a specific purpose. Consequently, only intentionally designed entities can count as artifacts. This excludes an unintentionally broken cup of coffee or an unforeseen car crash. Leaving aside the question of the purpose of art, which requires its own theoretical investigation, it follows that neither natural phenomena nor mere things nor contingently shaped objects can be works of art.

But this concept of artistic artificiality still has to be refined - due to the following reasons: Firstly, some works of art are occurrences rather than solid things as we can see when we consider an opera performance or a happening or interactive works. Hence, we should better think of works of art as entities located in space and time that need not be solid physical things. Secondly, the creation of a work of art may consist in the shapening or composing of natural entities. As for instance - landscape gardening or land art have shown, there is no inconsistency in the idea of objects that are both natural and artistic. Tbirdly, creating a work of art does not mean that the artist must physically shape or arrange material like stone, wood, steel, or sounds. As the classical avant-gardes in the early twentieth century have demonstrated, the exposition or declaration of an unmanipulated something in a special artworld-context can be sufficient for its becoming a work of art. Since Duchamps's ready-mades, examples for this fact are quite numerous in modern art history. Fourthly, artifacts need not be purposeful even if they sometimes are. Regularly, works of art do not serve any purpose apart from enabling an interesting aesthetic experience. And being the subject of an aesthetic experience is no instrumental-property or causal relation because aesthetic experiences cannot be evoked in a causal way; works of art are no means as knives are means for cutting bread. Even if they provide the opportunity of making an aesthetic experience, they cannot force someone to do so. The goodness of art is no instrumental goodness.

From these considerations we can conclude that if artificiality is a necessary condition for something being a work of art, it must be conceived of in a specific sense - due to the four reasons I have mentioned. Accordingly, a second answer

I. George Dickie, Introduction to Aesthetics: An Analytic Approach (New York and Oxford: Oxford University Press, I997), 87. 
to the question concerning the nature of works of art claims that works of art are intentionally created, made by man and located in time and space.

Even if we set aside the last point - the location of artifacts in time and space which causes theoretical problems concerning the ontological status of works of art -, another question arises: What is the difference between works of art and artifacts of any other kind? This question is part of what can be called the Dantoproblem: Why is - at least under certain circumstances - a tie painted blue by Picasso a work of art, whereas a tie that was painted blue by a child and looks exactly like Picasso's tie is no work of art?

I think that Picasso's tie is a sign whereas the tie of the child is not. Picasso's tie is used as an element of artistic expression or communication, and this usage leads to an artistic transfiguration of this commonplace-object. Regarding Picasso's tie as a sign of a certain kind, that is: as a work of art presupposes that it is a meaningful object intentionally created by an artist in order to express something. According to this, only artifacts used as signs of a particular kind can be called works of art. As many philosophers have pointed out, nothing but an investigation in the nature of artistic signs can reveal what art is all about.

It is the way we use signs that is responsible for the transformation of artifacts into artistic artifacts. This insight corresponds with many theories considering art as a special kind of human articulation or communication, as a non-verbal kind of language that provides various ways of expression. Striving for a closer explanation of this thesis, we have to pay attention to the fact that artistic expression is a kind of intentional expression: works of art express a meaning whereas - for instance - a face bas or showws a certain expression. The awareness of works of art having an intentional expression and being made for expressing a meaning belongs to the standard repertoire of the occidental philosophy of art. This thought is in spite of all the differences in detail - common to the aesthetics of pragmatism, structuralism, hermeneutic, semiotics, critical theory, deconstruction, and of many others.

But beyond this consensus we find that there is an ongoing dispute among all these theories about the character of signs of art and their particular properties. Since it is not feasible to go through all the different approaches, I shall concentrate on my own view whose method refers to Charles Morris's semiotic aesthetics.

Morris has pointed out that the analysis of works of art has to consider their semantic, syntactic and pragmatic properties in order to describe their specific status as signs. First I will turn to the semantic dimension of art that is acknowl- 
edged by most theories in the history of philosophical aesthetics. Since Plato exiled most of the arts from his ideal state because of their weakening effects and their distance from truth, there have not been any renowned theories contesting that works of art express a meaning (even if there are enormous differences regarding the nature of this meaning). In principle, the semantic dimension is confirmed by the simple fact that we cannot help interpreting works of art. Not the mere glance at a painting by Picasso, but the trial to understand the configuration of its form and subject, not the mere reading of a poem by Paul Celan, but the investigation in its deeper meaning is the way in which we are used to be occupied with works of art. From this fact we can conclude that artistic works ask for an understanding because they are perceived as signs bearing a meaning that normally is to be revealed first. They are significant entities whose meanings are not obvious, but require interpretation.

Claiming that the meaning of a work of art is constituted by the co-operation or interaction between its content and its form, I only repeat a well-known and often disputed opinion about the nature of works of art. The artistic meaning is as I suppose - the result of this interaction between content and form. In this context, "form" means technique, style or manner in which the subject or theme is carried out or presented. "Content" (or "subject") means the person, the fact, the event or the topic the work is about - may it be the fate of Ulysses, a sunset in the mountains or the obstinacy of pure colour. Both - form and content in their inseparable cooperation - produce what I would like to call "artistic configuration". Artistic configuration can be seen as the way in which is presented whatever a work of art presents, and that means: the specific perspective or viewpoint produced by the work. The artistic configuration simply is the point of view from which the content is presented by means of artistic form. The meaning of a work of art consists in the configuration arising from the interaction between form and content.

Therefore, we have to take into consideration both form and content if we want to interpret the meaning of a work of art. Only by studying the form in which the content is clothed, we are able to make a statement about what this work is about.

Summing up we can say: in contrast to signs used in our every-day life, signs that normally. conceal their form in order to facilitate interpersonal communication, works of art are presentations of both form and content. They expose their form in order to produce a specific perspective of their content.

My semantic approach to the signs of art specifies this thought by supposing that works of art articulate the way in which they constitute their own meaning. 
This sounds paradoxical, but it is not. For, if works of art are characterized as signs that - by means of their form - throw a particular light on their content, then the beholder, hearer or reader has to reconstruct the process in which this constitution of an artistic perspective is realized. Consequently, the meaning of a work of art and the way in which this meaning is constituted coincide.

The result of our semantic reflection can be confirmed by analysing the syntax of works of art. This analysis follows Danto's claim that a work of art should be seen as an analogy of metaphor. According to Max Black's "interaction theory" metaphors are syntactically composed by linking two notions. The first notion is used literally, whereas the second notion is used figuratively. Each notion is related to an amount of connotations or implications that accompany the main meaning and that are familiar to any natural speaker of the language in question. These connotations form a charateristic idea or perspective on the object the metaphor refers to. If we say: $M a n$ is a wolf, then we have in mind that man is a social being whose behaviour sometimes is not kind at all. On the other hand, using the metaphor we normally think of wolves as four-legged, dangerous animals hunting in packs and not shrinking back from killing each other in times of need. Even though the last supposition is wrong, the list of properties is the underlying basis of our normal usage of "wolf". Now a normal interpreter of the metaphor "Man is a wolf" will correlate the connotations of both notions and select intuitively those meanings corresponding to each other. Black calls this selection of corresponding meanings the interaction of the two notions. Eventually, this interaction results in an intricate network of corresponding meanings that constitute the content of the metaphorical expression as a whole. In our example this meaning could be the insight that man is a dangerous being that often tends to kill members of his own species. So, a metaphor develops a specific perspective on its subject by means of the interaction between literal and figurative expressions. In order to understand this meaning, the hearer or reader has to reconstruct the process of interaction by repeating the search for correspondences between both notions.

As to the syntactical approach to the signs of art, I take the view that the constitution of metaphorical meaning is analogous to the way in which works of art characterize their subject by means of their form. The syntactical structure of a metaphor (and that means: the interaction between the two notions) corresponds to the relationship between content and form in a work of art. Regarding metaphors it is the figurative expression that draws up a particular perspective on the literal notion, regarding art it is the form that shapes a particular perspective on 
the subject of the work. In both cases we have an element that is to be characterized and a characterizing element that stresses some properties of the first element. On the basis of this parallel structure and with regard to their syntactic dimension, I suppose that works of art should be seen as analogies of metaphors.

As far as the pragmatic dimension is concerned, an artifact only becomes a sign if it is used or regarded as something having a meaning. Generally, any perceptible entity can be used as a sign, even if there are considerable restrictions emerging from the fact that a sign has to be repeatable, easy to be used or remembered, that it should be at everyone's disposal etc. Nevertheless, it is the intersubjective use of an artifact that is responsible for this artifact's turning into a sign.

There are three conditions signs generally must meet: firstly, intersubjectively shared conventions for the use of signs, secondly the supposition that there is an intention of expressing something, and thirdly a particular situation in which the sign occurs. Works of art meet these conditions in the following way: Firstly they lack intersubjective conventions - at least in the sense that there are no semantic rules for an artistic medium analogous to the rules of natural language. By the way this is the reason why the meaning discovered by an individual interpretation will always slightly differ from all the meanings other interpreters have found.

But now we have to face this objection: If there are no conventions and if signs depend on conventional rules, how can it be that works of art are considered as signs at all? The answer is: there surely exist conventional rules, but these rules are much more unspecific and vague than rules of language. They consist in cultural expectations, institutional settings and social regularities that direct and regulate our perception and understanding of art. Secondly, we cannot take an artifact for a work of art without presupposing that there is an intentional expression in it: Whether we are right or wrong in doing so is of subordinate interest, because a blue tie remains a work of art as long as the most of us regard it as a masterpiece created by Picasso - even if it was coloured by a child. Thirdly, there is a difference between the fact that each work of art is regarded as having a meaning and the question what the work really means. That there is a meaning depends on the presupposition that we are dealing with a sign. But what the work is about is determined by the context of interpretation the interpreter chooses in order to reveal the content of the work. This interpretational context may consist in a theory, in historical information, in personal experience or in the knowledge about the biography of the artist - in each of these cases the contextual information helps us to reconstruct the interaction between form and content by providing a certain perspective of understanding. So we have to differentiate between two prag- 
matic aspects of artistic signs: the first applies to the institutional circumstances that make an artifact appear as a work of art; and the second aspect has to do with the contexts used to determine the meaning of the work.

As far as the first aspect is concerned, there can be no doubt that some social institutions are responsible for making a work of art out of any object - for instance: a museum, a bookshop, a concert-hall, the existence of institutionalized art criticism, the fact that art or literature are school subjects and all the social conventions and rules connected with these institutions. On the basis of these institutions we accept for example that the blue tie exposed in a show-case is a meaningful artistic sign - and not a bad joke.

As far as the second pragmatic aspect of artistic signs is concerned, we can see that there are informational contexts we mobilize in order to grasp the meaning of the work as well as possible. For example, the psychological concept of "double bind" is very helpful for the interpretation of Kafka's prose, and historical knowledge about the Spanish civil war is indispensable for the understanding of Picasso's Guernica. Apparently, this second pragmatic aspect relies on the first: Any artistic interpretation depends on the supposition that its object is a meaningful sign, and that means: a work of art. On the other hand, the first aspect - i.e. taking an object for a work of art according to its institutional contexts - is independent from the second -i.e. the interpretation of the work with the help of illuminating context information: this independence becomes evident in the fact that we often accept something - for instance a blue tie - as a work of art even if we are - at least at the moment - not able to say what it is about. As a result, the pragmatic dimension of signs of art includes two different aspects that do not coincide: the institutional contexts from which the work emerges, and the informational contexts providing interesting hints for the interpretation of its meaning.

Summarising my thoughts about the nature of artistic signs I can say that works of art should be characterized by explaining their semantic, syntactic and pragmatic dimension. From a semantic point of view, works of art have a meaning that arises from the interaction between form and content. As far as the syntactic dimension is concerned, works of art have shown to be similar to metaphors that present their objects from a certain point of view. And finally, considering the pragmatic dimension we find that an artifact is taken for a work of art due to its institutional context and that its meaning is interpreted with reference to illuminating informational contexts.

At the end I would like to add that the semiotic analysis of art I have concisely outlined is not restricted to modern art, but covers all kinds of art we know. The 
blue tie as well as a poem by Baudelaire or a tapestry of the Middle Ages or a sonata composed by Bach must meet relevant semantic, syntactic and pragmatic conditions in order to count as works of art today. 